\title{
MYXOMA OF HEART WITH NEUROLOGICAL SIGNS
}

\author{
by \\ PETER MILLS AND MAURICE PHILPOTT \\ From the Department of Medicine, Lister Hospital, Hitchin, Herts
}

Myxoma of the heart, although extremely rare, has received a certain amount of attention during the past fifteen years or so, being described by Yater (1931), Gilchrist and Millar (1936), Fawcett and Ward (1939), Thompson (1944), and Burnett and Davidson (1945). The tumour appears to arise always in one or other of the auricles, more often in the left, and the clinical presentation is usually one of progressive, relentless congestive heart failure without previous cardiac symptoms or signs.

The following case is thought to warrant publication, both on the grounds of the rarity of the condition and the fact that, although the final picture was one of congestive heart failure, the case originally presented with neurological symptoms which are unusual in this condition. These symptoms were presumably the result of emboli from the tumour itself or from thrombi forming on its surface. No mention seems to have been made in previous records of this type of presentation, apart from a patient reported by Gorlitzer (1934), who died suddenly; large emboli from a thrombus on the surface of the tumour were found in the cerebral arteries at necropsy, but apparently there had been no neurological signs during life.

\section{Case Report}

The patient, a man aged 44 years, was admitted to hospital in August, 1944, in a semi-comatose state. The history from his relations was that he had been vaguely unwell for some four weeks and had become increasingly drowsy two days before admission.

On examination he was found to have a left facial palsy of upper motor neurone type, and a flaccid left hemiplegia with left extensor plantar response. The heart was found to be slightly enlarged to the left, confirmed by radiography, but the sounds were normal and there were no murmurs. His blood pressure was $150 / 95$, and the pulse was regular. The cerebrospinal fluid protein content was $80 \mathrm{mg}$. per $100 \mathrm{ml}$., but the fluid was otherwise normal. White blood count, urine, blood urea, and skull X-ray were all normal, and the Wassermann reaction in blood and cerebrospinal fluid was negative. He gradually improved and was discharged from hospital one month after admission. At that time he had only slight weakness in the left limbs, which had now become slightly spastic, the plantar response remaining extensor.

Four months later, in January 1945, the patient was re-admitted owing to a sudden onset of generalized weakness, associated with a confused mental state. The previous day he had collapsed following a hot bath. He now had weakness of the left external rectus, and still had weakness with increased tendon reflexes and an extensor plantar response in the left leg. The left arm now appeared normal, and the facial palsy had recovered. Lumbar puncture still showed $80 \mathrm{mg}$. per $100 \mathrm{ml}$. of protein in the cerebrospinal fluid, which was otherwise normal, and the other investigations were still normal. He quickly recovered from the generalized weakness and confused mental state, and was discharged from hospital two weeks later. 
He remained well for ten months, and then began to develop shortness of breath and swollen ankles. For this he took to his bed, and, in spite of treatment from his own doctor, progressively got worse. On February 6, 1946, he was again admitted to hospital, and on examination was found to be very cyanosed and orthopnœic, with gross anasarca. The cardiac physical signs were unaltered, and the pulse, although raised in rate to 112, was regular in rhythm. His blood pressure was 140/80. Examination of the central nervous system was as on his previous admission. Treatment with digoxin and mersalyl had no effect, and venesection and paracentesis abdominis gave only a little temporary relief. The patient rapidly became weaker, and the congestion more marked. Some jaundice appeared, owing to hepatic congestion, and he died on February 13, 1946.

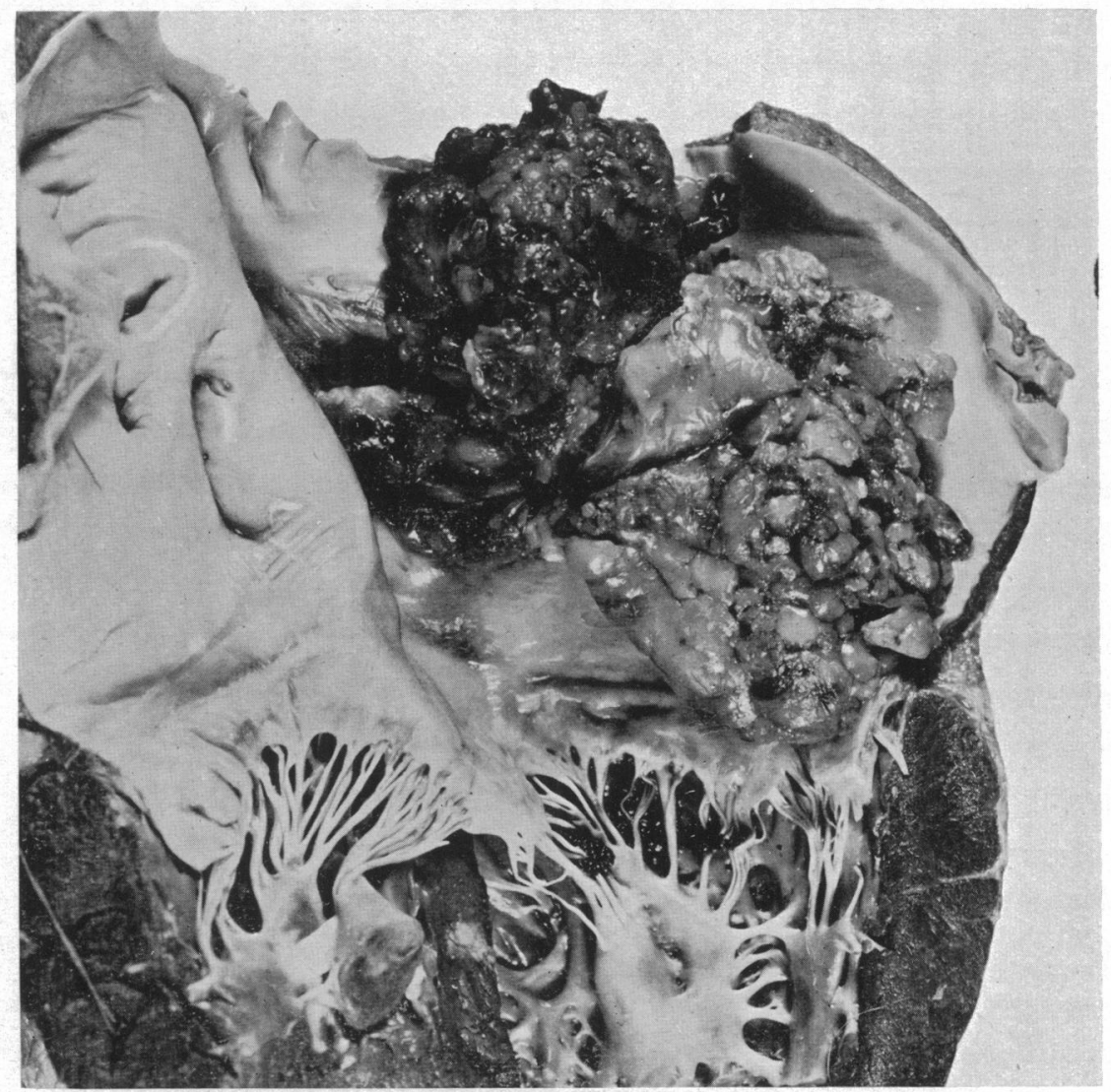

Fig. 1.-The left ventricle and auricle are opened showing the tumour in situ: it is attached by a peduncle to the posterior wall of the left auricle.

\section{Necropsy Report}

At necropsy the cause of death was found to be heart failure due to blockage of the orifice of the mitral valve by a pedunculated myxoma of the left auricle.

The tumour measured $5 \mathrm{~cm}$. from its attachment to its summit, and $6.5 \mathrm{~cm}$. from above down, and $4 \mathrm{~cm}$. from side to side. It was conspicuously villous. The villi had rounded, smooth tips. The tumour was very gelatinous and grey. Its central part was firmer, the cut surface here being pale yellow. It was attached by an extremely narrow, short pedicle $(0.4 \mathrm{~cm}$. diameter, $0.4 \mathrm{~cm}$. long) of tough tissue, to the left auricle $2.3 \mathrm{~cm}$. above the attached border of the posterior cusp of the 
mitral valve and $0.7 \mathrm{~cm}$. from the posterior border of the interauricular septum and immediately behind the annulus ovalis.

When the removed heart was held with the apex downward, the lower third of the tumour filled completely the orifice of the mitral valve. Both cusps of the mitral valve and the other three cardiac valves were normal. There was dilatation and hypertrophy of the left auricle $(13.5 \mathrm{~cm}$. circumference and $0.35 \mathrm{~cm}$. thickness), and of right ventricle $(0.6 \mathrm{~cm}$. thick), and of right auricle. There was no alteration in the left ventricle. The heart weighed $470 \mathrm{~g}$.

Microscopically, sections of the tumour showed very little tissue structure: just a fibrillated matrix with connective tissue cells sparsely scattered, and some areas of necrosis where there were no cells. Collagen fibres could not be demonstrated, and repeated efforts with special stains failed to show the presence of mucin.

In the rest of the necropsy there was pronounced evidence of chronic heart failure-' nutmeg' liver (weight $1100 \mathrm{~g}$.); hard, dark, red spleen (weight $135 \mathrm{~g}$.); bilateral pleural effusions (1.4 litre each) of straw-coloured fluid; ascites ( 1.7 litre); and pitting œdema of legs. Both kidneys (weight: left 290 g.; right: 200 g.) showed large sunken white scars of old infarction. The brain showed no macroscopic lesion in numerous sections.

\section{Discussion}

The previously recorded cases have been extensively reviewed by Fawcett and Ward (1939), who also described a case of their own, and further cases were described by Thompson (1944), by Burnett and Davidson (1945) and by Brewin (1948). Most of these cases presented with severe congestive heart failure, progressing rapidly and failing to respond to any form of treatment. In such cases the heart usually appeared normal on clinical examination except for disturbed rate. Thompson (1944), however, described a case in which systolic and diastolic murmurs were heard, and Gilchrist and Millar (1936) reported a case with paroxysmal tachycardia.

Hence, although this condition is extremely rare, it might well be borne in mind when one is presented with a case of severe congestive heart failure with no obvious cardiac lesion on clinical examination, especially when the onset has been sudden and the progress rapid, and where the condition fails to respond to treatment. The case here described is unusual in presenting at first with neurological physical signs.

We would like to express our thanks to Dr. Mary Brown of the Pathological department of the Lister Hospital, Hitchin, and to Dr. W. W. Woods of The Bernhard Baron Institute of Pathology, The London Hospital, for their help in the pathological description of this case, and to Mr. John King for the photograph.

\section{REFERENCES}

Brewin, T. B. (1948). Guy's Hosp. Rep., 97, 64.

Burnett, W., and Davidson, J. I. (1945). Brit. Heart J., 7, 180.

Fawcett, R. E. M., and Ward, M. E. (1939). Ibid, 1, 249.

Gilchrist, A. R., and Millar, W. G. (1936). Edinburgh med. J., 43, 243.

Gorlitzer, V. (1934). Zbl. allg. Path. path. Anat., 41, 115.

Thompson, R. B. (1944). Brit. Heart J., 6, 23.

Yater, W. M. (1937). Arch. intern. Med., 48, 627. 